\title{
Role of Muscle Strengthening Exercise on Osteoarthritis of the Knee Joint
}

ABUL KALAM AZAD, ${ }^{1}$ GOLAM NABI, ${ }^{2}$ MA SHAKOOR, ${ }^{3}$ MD. MOYEENUZZAMAN 4

\begin{abstract}
:
A total of 106 patients of osteoarthritis of knee were selected for the study. Out of 106 patients $26.41 \%$ were male and $73.58 \%$ were female. The female and male ratio is 2.78 : I. Mean age was $49.68 \pm 9.16$ years and house wives were maximum in number 75 (70.8\%). They were divided into two groups, 52 patients in group-A, were treated with NSAID plus Exercise and another 54 patients in group- $B$, were treated with NSAID only. In both group patients were treated for six weeks duration. The improvement was assessed with WOMAC scoring system. Student's' $t$ ' test was to see the level of significance. In present study, the patients groups those who received NSAID plus Exercise, improved more significantly $(p=0.001)$ than those who received NSAID only. So it can be concluded that quadriceps muscle strengthening exercise is effective in the patients with OA knee.
\end{abstract}

Keyword: Osteoarthritis, Knee, Exercise.

\section{Introduction:}

Painful knee is one of the common complaints for which the patients are attending the Physical Medicine and Rehabilitation Department. Osteoarthritis is the most important of the rheumatic disease and is responsible for a huge burden of pain and disability ${ }^{1}$. Pathologically it may be defined as a condition of synovial joint characterized by bifocal loss of articular hyaline cartilage and simultaneous proliferation of new bone with remodeling of joint contour. ${ }^{2}$ The pain is mechanical in nature. Sometimes prolong rest may precipitate the pain. ${ }^{3}$ Physical examination reveals nothing at the early stage. In advance case there is bony prominences, limitation of rang of motion, crepitation, painful range of motion, malalignment and/or joint deformity. ${ }^{4}$ Most of the case can be diagnosed clinically. ${ }^{3}$ Gender also influences the prevalence of OA. Isolated hand and knee $\mathrm{OA}$ are common in women, whereas the prevalence of hip is higher in men ${ }^{5}$. Knee OA is the leading cause of chronic disability in developed countries. Some 100000 people in United States are unable to walk independently from bed to bath room because of knee or hip OA. ${ }^{6}$ The management of osteoarthritis are pharmacological e.g.- Analgesic and NSAID, corticosteroid, glucosamin, hyaluronic acid, \& topical capsaicin, non- pharmacological e.g.- patient education, exercise, personal contact, physiotherapy, assistive device, patellar tapping, appropriate footwear, and surgery may be needed. ${ }^{7}$ In comprehensive management of the patients with OA should involve non-pharmacological interventions in combination with medication. Medication such as analgesics \&NSAID should not be used alone as the primary therapy but instead should be used in conjunction with non pharmacologic measure. ${ }^{5}$ The basic components for any physical activity program are exercise to improve flexibility, strength and endurance. The type of muscle contraction is static and dynamic. To improve joints ROM in OA patient static stretching is recommended. This stretching technique moves muscle, joints, and peri-articular tissues through a ROM that is comfortable for the patient but that produce some resistance to further movement. The board of directors of the American Geriatrics society (AGS), along with a multidisciplinary panel of experts recommended that the AGS take the lead in promoting exercise prescription for OA patients in the primary care setting. Another data which suggest that intervention designed to strengthen the muscle may be effective methods for reducing pain and improving functional capacity in patients suffering with OA. ${ }^{5}$ Quadriceps muscle weakness is a risk factor for OA knee which is often the consequence of the patient with OA knee. ${ }^{5}$ In this regard quadriceps muscles strengthening exercise have a great role to prevent $\&$ to improve the patients with

1. Medical Officer, Dept. of Physical Medicine \& Rehabilitation, Bangabandhu Sheikh Mujib Medical University, Dhaka, Bangladesh.

2. Medical Officer, Dept. of Physical Medicine \& Rehabilitation, Bangabandhu Sheikh Mujib Medical University, Dhaka, Bangladesh.

3. Associate Professor, Dept. of Physical Medicine \& Rehabilitation, Bangabandhu Sheikh Mujib Medical University, Dhaka, Bangladesh.

4. Professor and Chairman, Dept. of Physical Medicine \& Rehabilitation, Bangabandhu Sheikh Mujib Medical University, Dhaka, Bangladesh.

Corresponding author: Dr. Abul Kalam Azad, Department of Physical Medicine \& Rehabilitation, Bangabandhu Sheikh Mujib Medical University, Dhaka, Bangladesh. Email: dmashakoor04@yahoo.com 
OA knee. Through this study an attempt was made to find out the effect of quadriceps exercise on the patients with knee OA.

\section{Methodology:}

A prospective study was done in the Department of physical medicine \& rehabilitation, BSMMU, Dhaka. A total of 106 patients were taken for this study from January 2009 to June 2009 with the specific selection criteria - which were as follows:-

\section{Inclusion criteria-}

a) Patients of both sexes were included.

b) Age of the patients was -e 38 years and d"70 years.

c) Patients of primary OA of knee joints.

d) Patients with no morning stiffness or morning stiffness $<30$ minutes.

e) Patients with complaints of knee pain for more then 3 months.

f) No evidence of TB, malignancy, skin infection \& history of recent trauma.

\section{Exclusion criteria:}

a) The patients below the age of 38 years and above 70 years.

b) Patients with knee pain less then 3 month.

c) Patients with morning stiffness $>30$ minutes.

d) Patients with secondary OA knee.

e) Evidence of TB, malignancy \& skin infections over knee joints.

The selected patients will be divided randomly into the following two groups by the way of lottery. Group A : In this group 52 patients to be treated with NSAID \& quadriceps muscle strengthening exercise. Group B : In this group 54 patients to be treated only with NSAID. Quadriceps muscle strengthening exercise was given by a physiotherapist and it was done by the patient 10 repetitions twice daily. NSAIDs was given in the form of naproxen (250 mg) twice daily with omeprazole coverage. After taking inform consent of the patient, details history was taken and recorded \& a pre-set data form was filled for every patient. Past history of infection, trauma \& any systemic disease were inquired cautiously. Clinical examination was done systematically. Baseline investigation including complete blood count, blood sugar, RA factor, serum uric acid, creatinine, SGPT was done. Radiological examination in the form of x-ray knee joint both view was done \& the finding of all investigations were recorded in data sheet. Treatments were given according to the schedule \& followed up weekly for six weeks. All the patients were assessed initially \& weekly for six weeks. The data sheet was coded without the name of the patient. Assessment was done by a person who was not associated with selection of the patient, to make the assessment unbiased. Patients were assessed by Visual analogue scale and WOMAC scores. All the data was complied \& sorted properly and numerical data was analyzed statistically. The result was expressed as percentage and mean \pm SD and the level of significance by p-value unless otherwise stated. Statistical analysis was done by using statistical package for social science (SPSS) for windows. Student't' test was done. The study was approved by the ethical committee of BSMMU.

\section{Results:}

A total of 115 patients of OA knee were included in this study. But 9 patients were dropped out from the study because they cannot attend regularly for follow up and / or can not follow the treatment allocated to them properly. So, 106 patients follow the treatment allocated for them properly. Out of them, 78 (73.6\%) were female and 28 (26.4 $\%)$ were male and female to male ratio was 2.78: 1 . In our study, the mean age of the patients were $49.68 \pm 9.16$ years. Out of 106 patients, most of the patients of osteoarthritis of the knee joints were at the age group of 40 to 49 years (Fig.-1). The following table shows the age distribution of the study patients. Maximum female person became affected with OA knee in their earlier age than the male (Fig.-1). Regarding occupation of the patients, the most of the patients were housewives (HW, 70.8\%), then the second highest were the private serviceman (8.5\%) \& govt. serviceman (6.6\% each), and then the cultivator (4.7\%). There were some patients of different occupation in our findings; they were retired serviceman (3.8\%), labor (0.9 $\%$ ), businessman (2.8\%), driver (0.9\%), and security guard (0.90\%). There was significant improvement after treatment in Group-A. In respect to time point improvement, marked improvement was started to occur after one week ( $p=0.001$ $\%, \mathrm{CI}=6.94$ to 13.34 ) and the improvement gradually increased day by day. And after the end of treatment there was significant improvement $(\mathrm{p}=0.001,95 \% \mathrm{CI}=29.91$ to 40.12, Table -I). This indicates that treatments with Exercises plus NSAIDs are effective for the improvement of the patients with OA-knee joints. There was significant improvement after treatment in Group-B also. In respect to time point improvement, marked improvement was started 
to occur after one week ( $\mathrm{p}=0.004,95 \% \mathrm{CI}=6.29$ to 31.97 ) and the improvement gradually increased. And after the end of treatment there was significant improvement $(\mathrm{p}=0$, $95 \%$ CI $=21.55$ to 47.61, Table No-II). This indicates that treatment with NSAIDs is also effective for the improvement of the patients with OA-knee joints. In comparison between two groups, it was found that there was no significant difference in pre-treatment, $W_{1}, W_{2}, W_{3}$ and $\mathrm{W}_{4}$, assessment scores between the two groups i.e., there was no difference in improvement. More improvement was found in Group-A than Group-B after $5^{\text {th }}$ week $(\mathrm{P}=$ 0.003 and $95 \%$ CI was -12.47 to -2.70 ). Then it was found that the improvement was gradually increased in Group-A than Group-B. Finally, it was found that there was significant improvement in Group-A than Group-B after $6^{\text {th }}$ week $(\mathrm{P}=$ 0.001 and $95 \%$ CI was -14.77 to -5.01 , Table- III). Regarding Range of motion, in comparison between two groups, there was no significant difference (Table no-IV).

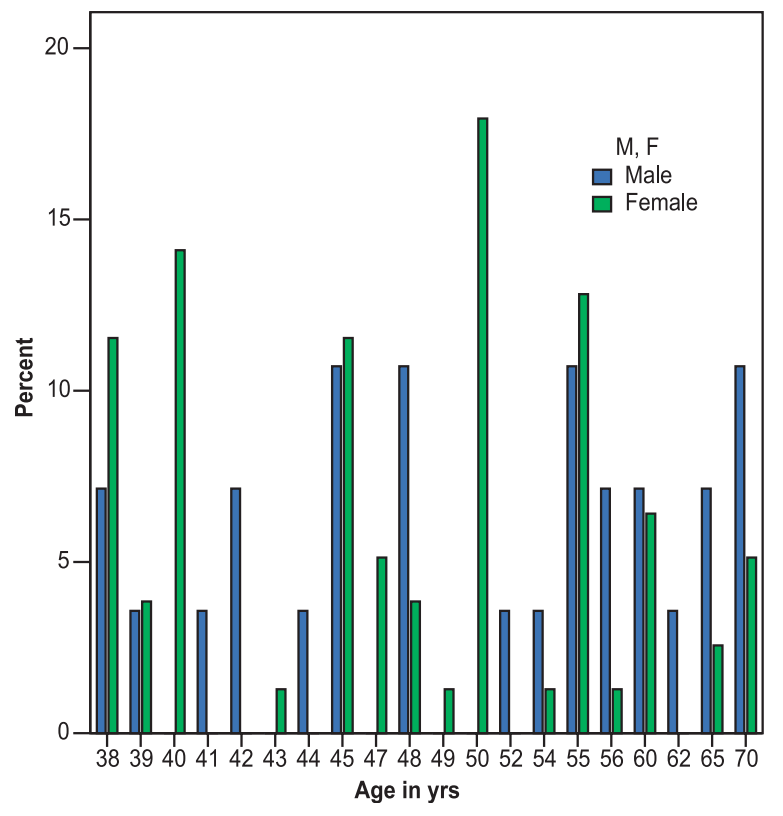

Fig.-I: Age distributions of the patients of both sexes with OA knee $(n=106)$.

Table-I

The time-point treatment responses of the patients in Group-A $(n=52)$.

\begin{tabular}{lccc}
\hline Time-point score & Mean \pm SD & p-value & 95\% CI \\
\hline Pre-treatment Vs W1 & $47.73 \pm 17.67$ Vs 37.58 \pm 15.17 & 0.001 & 6.94 to 13.34 \\
Pre-treatment Vs W2 & $47.73 \pm 17.67$ Vs 31.36 \pm 13.09 & 0.001 & 12.38 to 20.35 \\
Pre-treatment Vs W3 & $47.73 \pm 17.67$ Vs 26.24 \pm 13.86 & 0.001 & 16.96 to 26.01 \\
Pre-treatment Vs W4 & $47.73 \pm 17.67$ Vs 21.75 \pm 12.70 & 0.001 & 20.92 to 31.01 \\
Pre-treatment Vs W5 & $47.73 \pm 17.67$ Vs 16.97 \pm 11.21 & 0.001 & 25.75 to 35.76 \\
Pre-treatment Vs Post-treatment & $47.73 \pm 17.67$ Vs 12.70 \pm 10.21 & 0.001 & 29.91 to 40.12 \\
\hline
\end{tabular}

The results are expressed in mean \pm standard deviation (SD).

$\mathrm{n}=$ Number of the patients participated in the clinical trial.

$\mathrm{W}=$ end of the weak,

Table-II

The time-point treatment response of the Patients in Group-B $(n=54)$.

\begin{tabular}{lccc}
\hline Time-point & Score in mean \pm SD & p-value & 95\% CI \\
\hline Pre-treatment Vs score at W1 & $57.18 \pm 45.98$ Vs 38.05 \pm 16.56 & 0.004 & 6.29 to 31.97 \\
Pre-treatment Vs score at W2 & $57.18 \pm 45.9830 .75 \pm 14.71$ & 0.001 & 13.69 to 39.15 \\
Pre-treatment Vs score at W3 & $57.18 \pm 45.9828 .39 \pm 13.72$ & 0.001 & 16.32 to 41.24 \\
Pre-treatment Vs score at W4 & $57.18 \pm 45.9826 .74 \pm 13.81$ & 0.001 & 17.82 to 43.05 \\
Pre-treatment Vs score at W5 & $57.18 \pm 45.9824 .56 \pm 14.04$ & 0.001 & 19.46 to 45.60 \\
Pre-treatment Vs Post-treatment & $57.18 \pm 45.9822 .60 \pm 14.77$ & 0.001 & 21.55 to 47.61 \\
\hline
\end{tabular}

The results are expressed in mean \pm standard deviation (SD).

$\mathrm{n}=$ Number of the patients participated in the clinical trial.

$\mathrm{W}=$ end of the weak, 
Table-III

Comparative improvement of symptoms between Group-A and Group-B in different time points:

\begin{tabular}{lccccccc}
\hline Group & ${\text { Scoreat } \mathrm{W}_{0}}$ & Scoreat $\mathrm{W}_{1}$ & ${\text { Scoreat } \mathrm{W}_{2}}$ & Scoreat $\mathrm{W}_{3}$ & Scoreat $\mathrm{W}_{4}$ & Scoreat $\mathrm{W}_{5}$ & ${\text { Scoreat } \mathrm{W}_{6}}$ \\
\hline $\mathrm{A}(\mathrm{n}=52)$ & $47.73 \pm 17.67$ & $37.58 \pm 15.17$ & $31.36 \pm 13.09$ & $26.26 \pm 13.86$ & $21.75 \pm 12.70$ & $16.97 \pm 11.21$ & $12.70 \pm 10.21$ \\
$\mathrm{~B}(\mathrm{n}=54)$ & $57.18 \pm 45.98$ & $38.05 \pm 16.56$ & $30.75 \pm 14.71$ & $28.39 \pm 13.72$ & $26.74 \pm 13.81$ & $24.56 \pm 14.04$ & $22.60 \pm 14.77$ \\
95\% CI & -22.86 to 3.95 & -6.58 to 5.65 & -4.75 to 5.96 & -7.47 to 3.15 & -10.09 to .123 & -12.47 to-2.70 & -14.77 to -5.01 \\
\hline p-value & 0.164 & 0.881 & 0.824 & 0.423 & 0.056 & 0.003 & 0.001 \\
\hline
\end{tabular}

The results are expressed in mean \pm standard deviation (SD).

$\mathrm{n}=$ Number of the patients participated in the clinical trial.

$\mathrm{W}=$ end of the weak,

Table No-IV

Comparative improvement of range of motion in degree (ROM) after treatment between Groups.

\begin{tabular}{lcc}
\hline Group & Pre-treatment ROM & Post-treatment ROM \\
\hline A (n=52) & 146.739 .64 & $148.96 \pm 5.71$ \\
B (n=54) & 148.524 .07 & $149.81 \pm 1.36$ \\
p-value & 0.15 & 0.45 \\
$95 \%$ CI & -4.63 to 0.76 & -1.95 to 87 \\
\hline
\end{tabular}

The results are expressed in mean \pm standard deviation (SD). $\mathrm{n}=$ Number of the patients participated in the clinical trial.

\section{Discussion:}

In our study, 78 (73.58\%) were female and 28 (26.41\%) were male and female to male ratio was $2.78: 1$. In a study at Chittagong, Bangladesh, by Shakoor MA et al found that out of 162 patients 66 (40.7\%) of the patients were female and 99(59.3\%) were male. ${ }^{8}$ Female to Male ratio was 0.68:1. It may be the reason that people in the chittagong are more conservative. So female attendance in hospital is less. Although men and women are equally prone to development of OA, but more joints are affected in women than men. ${ }^{9}$ Delson DT et al. mentioned, female - male ratio is 1.58: 1 in the Framingham osteoarthritis study. ${ }^{10}$ Leach, et al. in his study stated this ratio is 1.4: $1{ }^{11}$ This is in favour of the findings of my study. The female preponderances may be due to more female attendance in the hospital than male because they are very much busy in their work and they may take consultations from doctors in the evening. In the present study, the mean age of the patients were $49.68 \pm 9.16$ years. In the other two studies, the mean age was found $53.14 \pm 7.7$ years and $55.44 \pm 7.40$ years and most of the subjects were of 50 to 59 years age group ${ }^{9,12}$. This is to some extent same as the result found in the present series. . In a study at Taiwan, $\mathrm{MH}$ Jan et al. found the mean age of the OA- knee patients was $62.4 \pm 1.3$ years. ${ }^{13}$ Felson DT et al. proposed the range between 63 to 94 years. ${ }^{10}$ This is higher than that of the present study as the life expectancy is more in America and their life style is also different than our country. There were marked improvement of symptoms within both the groups began to appear at the end of first week. At the end of fifth week significant improvement were observed between the groups. The trends of improvements were continued throughout the whole period of six weeks of study. At the end of $6^{\text {th }}$ week significant improvement of symptoms of both the groups were found. And, in comparison between two groups, the significant improvement was found in the group of patients who received exercise plus NSAIDs than that of the patients who were not advised exercise but received NSAIDs only. Shakoor MA et al., in a study at Chittagong, Bangladesh, found that quadriceps exercise and ADLs in patients with OA knee was beneficial to reduce symptoms. ${ }^{8}$ This is in favour of our study. Quadriceps muscle strengthening exercise is important for increasing of the muscles and it is evident that muscle strengthening exercise improves the condition of the patients with OAknee significantly found in various studies. ${ }^{14-17}$ In a study, it was found that home based exercise program can significantly reduce pain in OA- Knee joints. ${ }^{18}$ In our study, we also found marked reduction of knee pain in exercise groups. American College of Rheumatology subcommittee also recommended quadriceps strengthening exercise for knee OA. ${ }^{19}$ Quadriceps weakness is common among patients with OA-knee, in whom it had been believed to be a manifestation of disuse atrophy, which develops because of unloading of the painful extremity. ${ }^{19}$ In scientific review, Kenneth $\mathrm{D}$ et al found that an exercise program may be as effective in decreasing joint pain as treatment with an NSAID. ${ }^{20}$ Patient with hip and knee OA can participate conditioning exercise programs to improve fitness and health without increasing joint pain or increasing their requirement for analgesic agents or anti-inflammatory drugs. ${ }^{20}$ They 
described the preference of isometric exercises over isotonic exercises. But we also used isometric quadriceps exercise for the treatment of OA knee joint. In another study, it was found that isometric quadriceps muscle strengthening exercise has beneficial effects to reduce symptoms of OA knee joint ${ }^{21}$. It is also in favour of the present series.

In conclusion, it can be said that muscle strengthening exercise is effective in treating the osteoarthritis of the knee joints and thereby it reduces disability of the patients with O A knee.

\section{Conflict of Interest: None}

\section{References:}

1. Dieppe P. Management of osteoarthritis of hip and knee joints.: Current Opin Rheumatol . 1993 ; 5 : 487-493

2. Doherty M., Lonyon P, Ralston S H, Musculoskeletetal disorder: In: Davidson's principles \& practices of medicine; Boon NA, Colledge NR, Walker BR (eds). Edinburgh, Churchill livingstone, 2006, pp1065-1144

3. Rahman MS. Manual of physical Medicine and Rehabilitation. Approach to patients with knee pain, 2008, pp-59-64

4. Manek N. J, Lane N.E.; Osteoarthritis: Current Concepts in Diagnosis and Management: Journal of American Family Physician. 2000; 61(6): 1-13

5. American Geriatric Society Panel: Exercise prescription for older adults with OA pain: Consensus Practice Recommendation. JAGS 2001; 49:808-823

6. Brandt KD. Osteoarthritis; In: Harrison's principles of internal medicine: :Kasper DL, Braunwald E, Fauci AS, Hauser S, Longo DL, Jameson JL editors, $16^{\text {th }}$ edition, USA, The Mcgraw Hill medical publishing division, p2036-45

7. Choudhury MR, Zaman MM, Huq SM, Alam F, Hakim F, Saha PR, Haq SA: A review on osteoarthritis: JBCPS 2005:23(3):123-136

8. Shakoor MA et al. Effects of activity modification on the patients with osteoarthritis of the knee. Banladesh Med Red Counc Bull 2007; 33(2):55-59

9. Solomen L. Clinical feature of osteoarthritis. In: Ruddy S, Harris ED, Sledge CB, Budd RC, Sergent JS editors. Kelly's Textbook of Rheumatology. Philadelphia; WB Sanders. 2001: 1409-1418
10. Felson D T, Naimark A, et al. The Prevalence of knee osteoarthritis in the elderly. The Framingham Osteoarthritis study. Arthritis and Rheum 1987; 30:8914-15

11. Davis M A, Ettinger G H, Neuhaus J. M. The role of metabolic factors and blood pressure in association with Osteoarthritis of the knee. Proceedings of an Int. workshop on Epidemiology of Osteoarthritis. Resienburg, West Germany, October, 1987-1988

12. Shakoor MA, M N Huq, Khan A A, Moyeenuzzaman M. Presentation of patients with Osteoarthritis of knee joint- A study of 54 cases. The Healer 2003; 10(1): 20-25

13. Jan MH \& Lai JS. The effects of physiotherapy on osteoarthritic knee of female. J Formosan Med Asssoc 1991; 90 (10): 1008-1013

14. Chard J, Dieppe P. The case for non- pharmacologic therapy of osteoarthritis. In: Cronstien BN editor. Current Rheumatology reports. Philadelphia. Current science Inc. 2001; 5: 88-94

15. Fisher NM, White SC, Yack HM, Smolinki RJ, Pendergast DR. Muscle function \& gait in patients with knee osteoarthritis before and after muscle rehabilitation. Disability Rehabil 1997; 19: 47-55

16. Chemberlin MA, Care G, Harfield B, Physiotherapy in osteoarthrosis of knee joint - A controlled trial of hospital versus home exercise. Int. Rehab. Med 1982; 4: 101-106

17. Fitzgerald GK, Child JD, Rdge TM, Irrgang JJ, Agility and perturbation Training for physically active individual with knee osteoarthritis. Phys Ther 2002; 372-382

18. Thomas KS, Muir KR, Doherty M, Jones AC,O Reilly SC, Bassey EJ. Home based exercise programmed for knee pain and knee osteoarthritis; randomized controlled trial. BJM 2002; 5: 752

19. Almond RD, Hoehberg MC, Moskowitz RW, Schnitzer TJ. Recommendation for the Medical management of osteoarthritis of hip and knee- American College of Rheumatology subcommittee on Osteoarthritis guideline . Arthritis \& Rheumatism 2000; 43 (9) : 1905-1915

20. Brandit KD. Nonsurgical Management of Osteoarthritis with an emphasis on non pharmacological measures. Arch Fam Med 1995; 4:1057-164

21. Shakoor MA, Rahman MS, Azad AK and Islam MS. Effects of isometric quadriceps muscle strengthening exercise on chronic steoarthritis of the knee. Banladesh Med Red Counc Bull 2010; 36:20-22. 